\title{
Challenges in Reporting the COVID-19 Spread and its Presentation to the Society
}

\author{
JAKUB KUBICZEK, Department of Economic and Financial Analysis, University of Economics \\ in Katowice, ul. 1 Maja 50, 40-287 Katowice, Poland \\ BART七OMIEJ HADASIK, Department of Business Informatics, University of Economics \\ in Katowice, ul. 1 Maja 50, 40-287 Katowice, Poland
}

CCS Concepts: • Information systems $\rightarrow$ Digital libraries and archives; Retrieval effectiveness;

Additional Key Words and Phrases: COVID-19, daily infections, automation of reporting, results presentation, information quality, public health quality

ACM Reference format:

Jakub Kubiczek and Bartłomiej Hadasik. 2021. Challenges in Reporting the COVID-19 Spread and its Presentation to the Society. F. Data and Information Quality 13, 4, Article 19 (August 2021), 7 pages.

https://doi.org/10.1145/3470851

\section{INTRODUCTORY WORD}

Information on the current course of the COVID-19 pandemic is one of the many factors shaping public sentiment. By providing information on the daily results of new SARS-CoV-2 infections and deaths, nationals of countries can only assume (without rationale, i.e., only on the basis of the information provided) when further restrictions, and lockdown at a critical moment, will be introduced. These assumptions are based only on guesses resulting from the reactive, not the proactive, preventive policy of the central authorities regarding the spread of the coronavirus. This is confirmed by scientific research showing that the interest in areas related to health protection in a pandemic context mainly occurs in the case of government announcements concerning the introduction of further restrictions [1].

Incidence rates may also be the basis for government policy in the form of forward guidance. The administration may determine what level of disease will result in additional restrictions. An example of such strategy is the one of the Polish Government, launched on November 4, 2020, which envisages staging the introduced restrictions conditioned by weekly increases in the number of infections [2]. The governments of Great Britain [3], Germany [4], Australia [5] and South

The paper has received funding of the University of Economics in Katowice to cover costs of Gold Open Access APC. Authors' addresses: J. Kubiczek, Department of Economic and Financial Analysis, University of Economics in Katowice, ul. 1 Maja 50, 40-287 Katowice, Poland; email: jakub.kubiczek@edu.uekat.pl; B. Hadasik (corresponding author), Department of Business Informatics, University of Economics in Katowice, ul. 1 Maja 50, 40-287 Katowice, Poland; email: bartlomiej.hadasik@edu.uekat.pl.

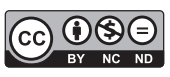
License.

(c) 2021 Copyright held by the owner/author(s).

1936-1955/2021/08-ART19

https://doi.org/10.1145/3470851
}

This work is licensed under a Creative Commons Attribution-NonCommercial-NoDerivs International 4. 0 
Africa [6] have taken similar steps. Another instance is the reference not only to the number of infections inside the country, but also to the epidemic situation in foreign countries. This type of examination is used in cases where there is a possibility of entering a given country from abroad or the possibility of crossing the border. The government of the Czech Republic introduces categories of countries according to their internal epidemic situation (determined by the average daily increase in infections), which - depending on the category assigned to a given country - results in the possibility of entering the country, quarantine conditions, and the capability of moving inside the country [7]. A similar classification was chosen by the Ministry of Health of Italy [8] and Switzerland [9]. However, there are countries such as Norway and Japan that (with a few exceptions) have withheld the possibility of entering the country, regardless of the epidemic situation of the country a person came from $[10,11]$.

Ameliorating the quality of publicly presenting the results of COVID-19 incidence rates clearly affects social behavior and drives government response. This paper explores three important challenges in the context of information quality in a pandemic, facing national governments, and society at large. These are: (1) misinformation, (2) seasonality of data, and (3) no frame of reference. These challenges are the axes of the subsequent sections.

\section{MISINFORMATION}

Data shared on social media is an important source of information for mobile users [12] but it is information quality (IQ) that plays the most important role in shaping the users' behavior [13, 14]. On the other hand, the Internet is full of worthless information, as well as false or misleading news (so-called "fake news") which can cause fear and anxiety in the recipient [15, 16]. Information containing a suggestion is also often enriched, colored or changed in terms of knowledge possessed by the recipient of the information, as well as the context [17]. Thus, the framing effect is visible. People draw conclusions based on the information presented to them in the media. Hence, it is very important to follow only proven, reliable information from official and scientific sources, where the risk of giving wrong information is low, as right information is the basis for rational decision-making.

Decisions to share official information concerning COVID-19 spread, vaccination and healthrelated statistics on official social networks of the World Health Organization (WHO) or local health ministries (e.g., on Twitter, as in the UK [18, 19], India [20], or Poland [21]), may contribute to the proper informing of the public and the elimination of the uncertainty phenomenon. Scientific research shows that the availability of IT tools providing access to information (ICT) contributes to the reduction of uncertainty in crisis conditions [22]. Social media is considered to be the appropriate medium for communicating the necessary information, due to the large number of recipients and public reliability [23].

At this point, one should also mention the existing phenomenon known as "infodemic", which was defined by WHO. It refers to the flood of information concerning a problem (mainly in the context of the prevailing COVID-19 pandemic) causing a detriment to fight it, and containing both true, false and unverified information, as well as merely opinions [24, 25]. In the era of the coronavirus pandemic, this type of communication can be compared to the notion of "risk communication" also defined by WHO as "the exchange of real-time information, advice and opinions between experts and people facing threats to their health, economic, or social well-being” [26]. The battle against disinformation and "fake news" during the coronavirus pandemic is considered one of the most predominant issues in the context of reducing the spread of the disease and raising public awareness. This is demonstrated on the website "COVID-19 MISINFO" [27] which is dedicated to the steady fight against disinformation in the form of publishing reports, and providing advice on recognizing false information. 


\section{SEASONALITY OF DATA}

The direct reasons for the high seasonality of data should be seen in the process of reporting to central systems. In Poland, laboratories conducting tests for the presence of SARS-CoV-2 coronavirus infection are obliged to submit a report on the test results to the central system within a maximum of 48 hours [28]. A centralized system facilitates communication with citizens and provides reliable knowledge, but it is worth paying attention to the method of data transfer to the system. It is done manually by employees of research laboratories and thus it requires time - consequently, a delay between the test performed (and thus the results obtained) and the actual viewing of the results in the database occurs. Therefore, it is recommended to implement a solution in the form of integrating the IT systems of laboratories with the central one.

Automation of the results' transfer is another recommendation for systemic changes in the reporting process. The suggestion is to automatically send the result to the central system after each performed test. Due to the fact that the workflow in each research facility is different, as well as the local systems responsible for collecting and processing data, it is suggested to create a program managed by the central authorities in the form of a universal plug-in, applet or macro. It would be triggered when the data is transferred to the local laboratory database and would collect anonymized test data (i.e. excluding personal data) in the form of: test result (positive/negative), test type (i.e. PCR, antigen, etc.) as well as the unit performing the test. The plug-in could collect and send these data automatically (with the prior confirmation of the laboratory technician) or, in the event of an inability to automatically collect the data, these basic data would be entered by a laboratory worker. Sending data in real time to the central system would eliminate (or significantly minimize) human error contained in collective reports, and would also give greater state control over the flow of information on such a key issue for public health and thus for state security. Validity and accuracy of data during the data collection phase is seen as critical to further data processing and decision-making [29].

The effect of the observed seasonality of data is that it is presented in a way that does not allow direct day-to-day comparisons but merely week-to-week. This delays the government's presentation of ad hoc (reactive) preventive solutions and hinders or postpones the implementation of a reliable preventive policy to combat the spread of the coronavirus (proactive measures). Increasing the efficiency of the testing process may translate into better data quality - primarily, if data is entered into the central system promptly, data overlapping and unnatural drops and rises around non-working days or public holidays will be avoided.

\section{NO FRAME OF REFERENCE}

The published data including only the number of new infections without the number of tests performed can be called incomplete. Adding the knowledge that the average citizen is guided by such data, it can be regarded as misleading them. Without a point of reference, the effectiveness of the decision-making process deteriorates and may lead to erroneous conclusions [30, 31].

Presenting and determining the progress of a pandemic in terms of absolute values raises significant problems. First, when looking at infection data, there are no visible smooth trendlines marking a trend, but noticeable tiers. The trend in the form of a smooth line is only visible if taking into account the weekly average, which is discernible in the Figure A1 (Appendix). Such a situation is the result of many aspects that interfere with each other, and simultaneously are factors of a relatively permanent nature. Thus, the perceivable disturbances in reporting cannot be eliminated completely, as less testing capacity is observed during non-working days. As a result, the number of new infections published on some days of the week is, on average, higher/lower than on other days. 
The issue of the lack of a frame of reference is in this case unambiguously connected with the problem of data seasonality. The presence of seasonality in data creates a second problem in the context of absolute values, making it impossible to compare data on the basis of numbers without taking this seasonality into account. For instance, the occurrence of two consecutive days - a dayoff (Sunday) and a working day (Monday), may be the result of a dynamic increase in the number of infections after the weekend. An analogous situation is observed after national holidays.

Corrections in data are another aspect that distorts the absolute values. In the People's Republic of China on February 12, 2020, there was a noticeable sudden surge in the number of detected cases [32]. However, it should be noted that this influx was the result of adding to the statistics the cases that had not been included before.

Solving the problem of publishing solely absolute values is not a complicated task. Additionally, the number of coronavirus tests performed on the previous day should be provided. This would make it possible to obtain the percentage of positive tests. Nonetheless, in the case of large differences between the daily number of tests performed, the detection rate should be related to the same day of the week or period (e.g. weekly). Therefore, it is recommended not to juxtapose two consecutive days of the week, but to publish a trend change (e.g. a 7-day moving average). Relativizing the data in this way may be helpful in overcoming the problems with data interpretation and thus reduce people's anxiety.

Another issue worth raising in comparing data from different periods is the change of methodology in data collection. In the case of data concerning the spread of SARS-CoV-2 virus, a methodology change may be considered to include daily tests performed in the private sector, i.e. self-funded tests, not from a doctor's referral.

The solution to the problems of data seasonality and the lack of a point of reference may lie in the way the data is presented, taking into account the wider context, i.e., including additional information and the use of modern visualization tools (such as interactive dashboards including $[33,34])$. Educating the public to look at the disseminated data broadly is important, but the notion of "accessibility heuristics" [35] should also be borne in mind. It may result in the fact that even knowledgeable people can make emotional (irrational) decisions and draw inappropriate conclusions when information is distorted or not fully transparent. Therefore, it is the mass media facing a huge challenge to present the data on the COVID-19 pandemic - on the one hand in an accessible and transparent manner, and on the other, to maintain a broad and appropriate context.

\section{CONCLUSIONS}

According to the theory of decision making, the selection process is influenced by many aspects. However, two of them deserve to be highlighted: rational (based on information) and behavioral (based on emotions). Emotions are ultimately triggered by the perception of information. The more negative the emotion is, the stronger the fear is. A particular threat to the effectiveness of decision-making is the reliance on emotions caused by false, unreliable or incomplete information.

The first observed problem in the context of information quality during the COVID-19 pandemic is misinformation. On the one hand, social media facilitates access to information, but on the other, the multitude of information causes "fake news" to penetrate into human consciousness and this increases the feeling of insecurity. It is essential to present information in the right context and to adapt awareness-raising activities to verify the shared news.

The second issue considered when disclosing information to the public was the strong seasonality of new cases emergence. It should be noted that it is present in almost all countries in the world and if this seasonality does not occur, the credibility of the data should be confirmed. The lack of seasonality is observable in Egypt and Iran, where the increase of new cases is of a linear function. In order to eliminate this phenomenon, the solution is to create an automated tool for transferring 
test results to the central system which will send data immediately after obtaining results. It is also recommended to establish a network of all laboratory facilities (state and commercial) and extend their working hours by all days of the week with a state subsidy to overtime.

Seasonality is closely related to the third problem in providing values - the lack of data relativization. Referring only to absolute values distorts perception. This can be better illustrated by the following example: The percentage of 10 people infected is completely different when 100 people were tested, and different when 10 cases of infection were detected, but 1000 people were tested. Hence, it is recommended, in addition to publishing the number of new cases, to report the number of tests performed and refer the increase in infected data to the same period. It is possible to base this on the weekly trend which would eliminate the fluctuations in relation to the day of the week.

\section{A APPENDIX}

As additional material to this work, graphs of coronavirus daily infections for several countries are presented (for the period from February 24 to March 25, 2021), which reflect the discussed problem of data seasonality. Six countries were selected: Poland, Brazil, Armenia, Slovakia, South Africa, and Iran. In all countries (except Iran) there is a noticeable seasonality in infection data,
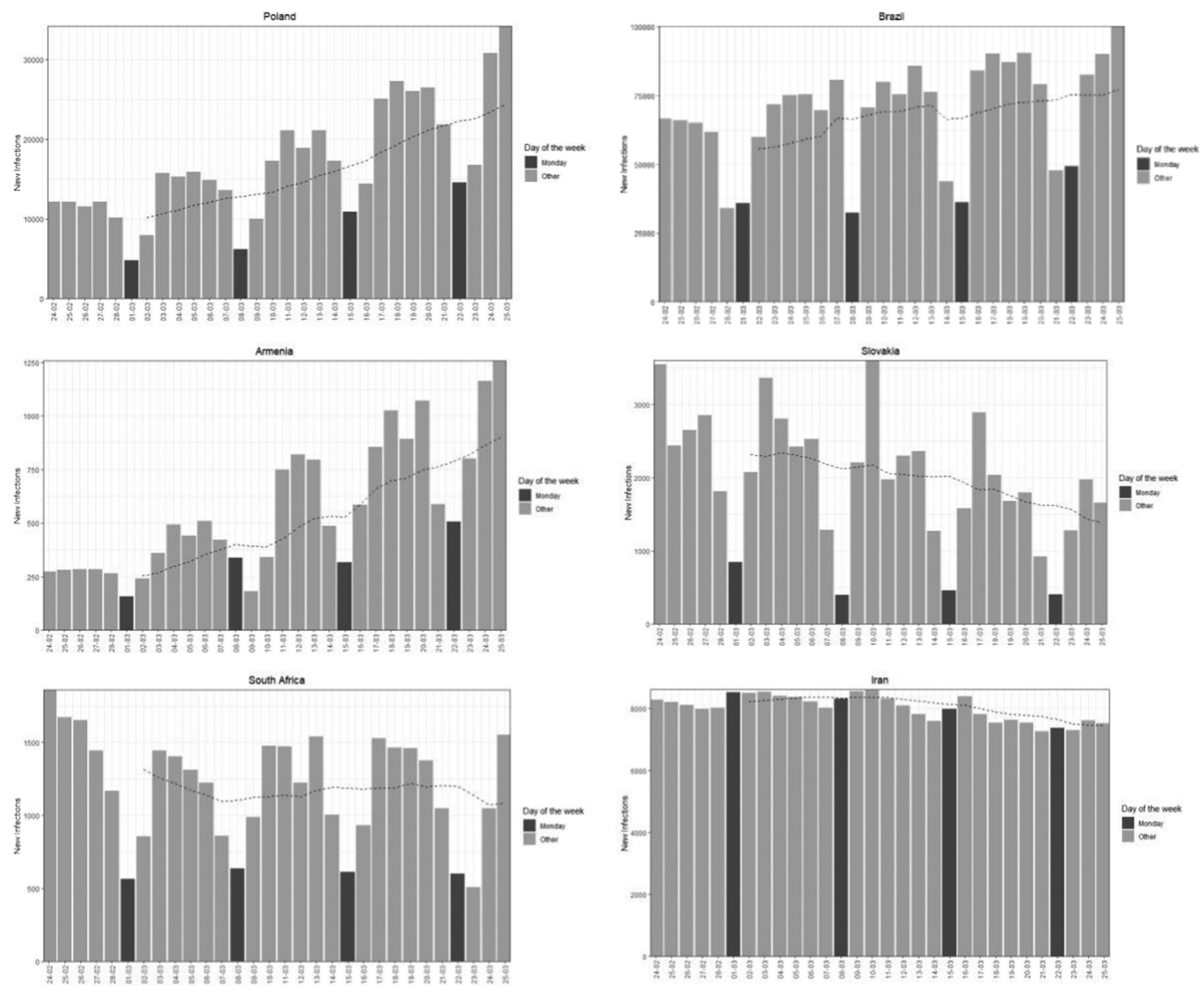

Fig. A1. Coronavirus infection daily increments (for the period from February 24 to March 25, 2021) for the following countries: Poland, Brazil, Armenia, Slovakia, South Africa, and Iran. Source: Own study based on [34]. 
with a significant drop immediately after the weekend (mainly on Mondays, highlighted in a dark shade in the Figure A1). Only in the case of the average number of cases from the previous seven days (marked with a dashed line in Figure A1) a linear trend is noticeable. Iran has a relatively constant number of infections per day, regardless of the day of the week. The coronavirus spread data that was used to create the graphs in Figure A1 comes from a database that aggregates official COVID-19 data in real-time [34].

\section{REFERENCES}

[1] A. Strzelecki, A. Azevedo, and A. Albuquerque. 2020. Correlation between the spread of COVID-19 and the interest in personal protective measures in Poland and Portugal. Healthcare 8, 3 (2020), 203. D0I:https://doi.org/10.3390/ healthcare 8030203

[2] Kancelaria Prezesa Rady Ministrów. Nowe kroki w walce z koronawirusem - ostatni etap przed narodową kwarantanną. Retrieved March 26, 2021 from https://www.gov.pl/web/premier/nowe-kroki-w-walce-z-koronawirusemostatni-etap-przed-narodowa-kwarantanna.

[3] Gov.uk (Cabinet Office). COVID-19 Response - Spring 2021 (Summary). Retrieved March 27, 2021 from https://www. gov.uk/government/publications/covid-19-response-spring-2021/covid-19-response-spring-2021-summary.

[4] DW.com. Coronavirus: Germany extends lockdown with plan to relax restrictions. Retrieved March 27, 2021 from https://www.dw.com/en/coronavirus-germany-extends-lockdown-with-plan-to-relax-restrictions/a-56763824.

[5] Australian Government. Framework for National Reopening. Retrieved March 27, 2021 from https://www.australia. gov.au/content/dam/australia/news-and-updates/framework-national-reopening.pdf.

[6] South African Government. About alert system. Retrieved March 27, 2021 from https://www.gov.za/covid-19/about/ about-alert-system\#.

[7] Ministry of the Interior of the Czech Republic. Coronavirus - information of MoI. Retrieved March 25, 2021 from https://www.mvcr.cz/mvcren/article/coronavirus-information-of-moi.aspx.

[8] Ministero della Salute. Covid-19, Travellers. Retrieved March 25, 2021 from http://www.salute.gov.it/portale/ nuovocoronavirus/dettaglioContenutiNuovoCoronavirus.jsp?lingua=english \&id=5412\&area=nuovoCoronavirus \& menu=vuoto.

[9] Swiss Federal Office of Public Health. Coronavirus: FOPH list of risk countries. Retrieved March 25, 2021 from https:// www.bag.admin.ch/bag/en/home/krankheiten/ausbrueche-epidemien-pandemien/aktuelle-ausbrueche-epidemien/ novelcov/empfehlungen-fuer-reisende/liste.html.

[10] Government.no. Travel to Norway. Retrieved March 25, 2021 from https://www.regjeringen.no/en/topics/korona virus-covid-19/travel-tonorway/id2791503/.

[11] Ministry of Foreign Affairs of Japan. Phased measures for resuming cross-border travel. Retrieved March 25, 2021 from https://www.mofa.go.jp/ca/cp/page22e_000925.html.

[12] S. J. Miah, N. Hasan, R. Hasan, and J. Gammack. 2017. Healthcare support for underserved communities using a mobile social media platform. Information Systems 66, 1-12. DOI : https://doi.org/10.1016/j.is.2017.01.001

[13] J. M. Grohol, J. Slimowicz, and R. Granda. 2014. The quality of mental health information commonly searched for on the internet. Cyberpsychology, Behavior, and Social Networking 17, 4 (2014), 216-221. DOI : https://doi.org/10.1089/ cyber.2013.0258

[14] L. Xiao and J. Mou. 2019. Social media fatigue -technological antecedents and the moderating roles of personality traits: The case of WeChat. Computers in Human Behavior 101, (2019), 297-310. DOI : https://doi.org/10.1016/j.chb. 2019.08.001

[15] A. Kumar and K. R. Nayar. 2020. COVID-19 and its mental health consequences. fournal of Mental Health 30, 1 (2020), 1-2. DOI : https://doi.org/10.1080/09638237.2020.1757052

[16] S. A. Lee. 2020. Coronavirus anxiety scale: A brief mental health screener for COVID-19 related anxiety. Death Studies 44, 7 (2020), 393-401. DOI : https://doi.org/10.1080/07481187.2020.1748481

[17] B. Wojciszke. 2011. Psychologia Społeczna (1st ed.). Wydawnictwo Naukowe Scholar. ISBN: 9788373834538

[18] Twitter. NHS. Retrieved March 27, 2021 from https://twitter.com/NHSuk.

[19] Twitter. Public Health England. Retrieved March 27, 2021 from https://twitter.com/phe_uk.

[20] Twitter. \#IndiaFightsCorona. Retrieved March 27, 2021 from https://twitter.com/covidnewsbymib.

[21] Twitter. Ministerstwo Zdrowia. Retrieved March 27, 2021 from https://twitter.com/MZ_GOV_PL.

[22] C. Koettl. 2017. Sensors everywhere: Using satellites and mobile phones to reduce information uncertainty in human rights crisis research. Genocide Studies and Prevention 11, 1 (2017), 36-54. DOI : http://doi.org/10.5038/1911-9933.11.1. 1440 
[23] S. Lawes-Wickwar et al. 2021. A rapid systematic review of public responses to health messages encouraging vaccination against infectious diseases in a pandemic or epidemic. Vaccines 9, 2 (2021), 72. DOI : https://doi.org/10.3390/ vaccines 9020072

[24] J. Zarocostas. 2020. How to fight an infodemic. The Lancet. 395, 10225 (2020), 676. DOI : https://doi.org/10.1016/s01406736(20)30461-X

[25] J. Y. Cuan-Baltazar, M. J. Muñoz-Perez, C. Robledo-Vega, M. F. Pérez-Zepeda, and E. Soto-Vega. 2020. Misinformation of COVID-19 on the Internet: Infodemiology Study. FMIR Public Health and Surveillance 6, 2 (2020), e18444. DOI : https: //doi.org/10.2196/18444

[26] World Health Organization. General information on risk communication. Retrieved March 26, 2021 from https:// www.who.int/riskcommunication/background/en/.

[27] Collaboratorium for Social Media and Online Behavioral Studies (COSMOS). COVID-19 MISINFO. Retrieved May 16, 2021 from https://cosmos.ualr.edu/covid-19.

[28] Mazowiecki Urząd Wojewódzki w Warszawie. Nowy system raportowania przypadków COVID-19 - ruszyła strona z raportem zakażeń Sars CoV-2. Retrieved March 27, 2021 from https://www.gov.pl/web/uw-mazowiecki/nowysystem-raportowania-przypadkow-covid-19-ruszyla-strona-z-raportem-zakazen-sars-cov-2.

[29] H. G. Miller and P. Mork. 2013. From data to decisions: A value chain for big data. IT Professional 15, 1 (2013), 57-59. DOI : https://doi.org/10.1109/mitp.2013.11

[30] Noreen H. Klein and Janet E. Oglethorpe. 1987. Cognitive reference points in consumer decision making. In Melanie Wallendorf and Paul Anderson, eds. NA - Advances in Consumer Research. 14. Provo, UT, 183-187. Retrieved March 25, 2021 from https://www.acrwebsite.org/volumes/6682/volumes/v14/NA\%20-\%2014.

[31] G. J. Koop and J. G. Johnson. 2010. The use of multiple reference points in risky decision making. Fournal of Behavioral Decision Making 25, 1 (2010), 49-62. DOI : https://doi.org/10.1002/bdm.713

[32] Worldometer.info. How to interpret the 15,152 surge in COVID-19 new cases of February 12. Retrieved March 29, 2021 from https://www.worldometers.info/coronavirus/how-to-interpret-feb-12-case-surge/.

[33] Center for Systems Science and Engineering (CSSE) at Johns Hopkins University (JHU). COVID-19 Dashboard. Retrieved May 16, 2021 from https://www.arcgis.com/apps/dashboards/bda7594740fd40299423467b48e9ecf6.

[34] E. Dong, H. Du, and L. Gardner. 2020. An interactive web-based dashboard to track COVID-19 in real time. The Lancet Infectious Diseases 20, 5 (2020), 533-534. DOI : https://doi.org/10.1016/s1473-3099(20)30120-1

[35] N. Schwarz. 1998. Accessible content and accessibility experiences: The interplay of declarative and experiential information in judgment. Personality and Social Psychology Review 2, 2 (1998), 87-99. DOI:https://doi.org/10.1207/ s15327957pspr0202_2

Received April 2021; revised May 2021; accepted June 2021 